\title{
DETERMINAÇÃO DOS TEORES DE ELEMENTOS MINERAIS EM ALIMENTOS CONVENCIONAIS E NÃO CONVENCIONAIS DA REGIÃo AMAZÔNICA PELA TÉCNICA DE ANÁLISE POR ATIVAÇÃO COM NÊUTRONS INSTRUMENTAL.
}

\section{Lúcia K.O. YUYAMA', Jaime P.L. AGUIAR', Sonja H.M. MACEDO', Tereza GIOIA', Kaoru YUYAMA², Déborah I.T. FÁVARO ${ }^{3}$, Cláudia AFONSO ${ }^{3}$, Marina B.A. VASCONCELLOS ${ }^{3}$, Silvia M.F. COZZOLINO4.}

RESUMO - No presente trabalho sào apresentados valores de concentraçào para os elementos minerais $\mathrm{Ca}, \mathrm{Fe}, \mathrm{K}, \mathrm{Mn}, \mathrm{Na}$, Se e $\mathrm{Zn}$ em alimentos convencionais e não convencionais da região Amazônica, obtidos por análise por ativação neutrônica instrumental. As concentrações dos elementos minerais nos alimentos analisados, variaram, sendo que o potássio se sobressaiu com teores expressivos na jaca (caroço e polpa) e graviola. Dentre os minerais, o selênio foi o que apresentou menor concentração nos alimentos analisados. Entretanto, notadamente importantes foram as concentrações verificadas na graviola, pupunha fruto e palmito.De acordo com os resultados obtidos sugere-se a indicação dos mesmos na alimentação diária dos amazonenses e espera-se contribuir na elaboração de tabelas de composição de alimentos regional e nacional. Palavras chave: Minerais, frutos, olerícolas e análise por ativação com nêutrons instrumental.

Determination of Concentration of the Mineral Elements in Conventional and Non Conventional Foodstuffs from Amazon Region by Instrumental Neutron Activation Analysis.

ABSTRACT - In the present work the concentration values of the mineral elements $\mathrm{Ca}, \mathrm{Fe}$, $\mathrm{K}, \mathrm{Mn}, \mathrm{Na}, \mathrm{Se}$ and $\mathrm{Zn}$ in conventional and non-conventional foodstuffs from Amazon Region by instrumental neutron activation analysis are presented. The concentrations to minerals varied according to the foodstuffs analysed. The highest concentrations of potassium were detected in jaca fruit (kernel and pulp) and graviola fruit. Although selenium was among the least abundant minerals, it was found in higher concentrations in graviola fruit, pupunha fruit and palm. Based on the concentration data of mineral elements it can be recommended the consumption of these foodstuffs in the daily meals of Amazonian people and we hope to contribute towards elaboration of regional and national food composition tables.

Key words: Minerals, fruits, vegetables and instrumental neutron activation analysis.

\section{INTRODUÇÃO}

A região Amazônica se caracteriza por uma disponibilidade de frutos ricos em pró-vitamina A (AGUIAR et al., 1980) e alimentos com elevado potencial econômico e nutricional (CLEMENT \& SILVA FILHO, 1994; LEHTI, 1993; ROCHA et al., 1982). Entretanto, há muito o que se estudar em relação aos teores de minerais nos alimentos convencionais e não convencionais da região Amazônica, uma vez que, pouco se sabe sobre a composição real desses elementos.

Nos últimos anos tem crescido sensivelmente o interesse na determinação de vários elementos essenciais e tóxicos em alimentos e dietas. Do ponto de vista

1 Laboratório de Nutrição e Físico-Química de Alimentos -CPCS/INPA-Alameda Cosme Ferreira 1756, Aleixo, Manaus, AM. CEP- 69083-000.

2 Coordenação de Pesquisas em Ciências Agronômicas-CPCA/INPA. Al. Cosme Ferreira 1756, Aleixo, Manaus, AM. CEP-69083-000.

3 Supervisão de Radioquímica - IPEN/CNEN - São Paulo

4 Laboratório de Alimentos e Nutrição Experimental - FCF/USP - São Paulo 
nutricional, está focalizado, principalmente, na adequação de nutrientes essenciais, presentes nas dietas consumidas diariamente pela população em geral. Por outro lado, toxicologistas estão preocupados com os niveis de certos metais pesados em alimentos.

Existe, então, a necessidade de se ter métodos analíticos confiáveis para a monitoração de dietas e alimentos para elementos minerais (macro e micro), pois eles são nutricionalmente e toxicologicamente importantes (CHATT et al., 1988).

A análise por ativação com nêutrons instrumental (AANI) tem sido de grande importância em diversos campos da Ciência, como por exemplo: em geoquímica, na análise de rochas, solo ou minério, destacando-se principalmente na análise de terras raras; em humanos na análise de cabelos, unhas, sangue, urina, tecidos de orgãos, analisados tanto instrumentalmente quanto empregando métodos de separação radioquímica (RNAA).

No atual controle da qualidade dos alimentos a AANI tem sido aplicada, com sucesso, principalmente na determinação de $\mathrm{Hg}, \mathrm{Se}, \mathrm{As}$, Sb e também de $\mathrm{Cr}, \mathrm{Cu}, \mathrm{Zn}$, $\mathrm{Co}, \mathrm{Rb}, \mathrm{Fe}, \mathrm{Br}$, entre outros elementos (TRANVAN \& TEHERANI, 1988; WOITTIEZ \& IYENGAR, 1988; LIU \& CHUNG, 1992; ZAIDI et al., 1992).

Métodos analíticos de alta precisão, exatidão e sensibilidade são necessários para a medição de níveis muito baixos de diversos elementos em amostras de alimentos. AAANI em suas várias formas é conveniente para este propósito.

Considerando-se que pouco se sabe sobre a real composição dos teores de minerais nos alimentos, frutos e olerícolas, convencionais e não convencionais da Região Amazônica e a importância do conhecimento, a fim de auxiliar na minimização dos problemas de nutrição em saúde pública, e também a variação da composição dos alimentos em função das condições ecológicas, o presente estudo tem como objetivo, determinar os teores de minerais nos alimentos convencionais e não convencionais da Região Amazônica, utilizando o método de Análise por Ativação com Nêutrons Instrumental.

\section{MATERIAL E MÉTODOS}

Foram analisados os seguintes frutos e olerícolas:

1. Graviola (Annona muricata L)

2. Abricó (Mammea americana L.)

3.Jaca/caroço (Artocarpus heterophyllus Lam.)

4. Jaca/polpa (Artocarpus heterophyllus Lam.)

5. Pupunha 2a. var. fruto (Bactris gasipaes Kunth)

6. Manga (Mangifera indica L.)

7.Cupuaçu (Theobroma grandiflorum (Will ex Spreng) Schum.)

8. Quiabo de metro (Trichosanthes cucumerina L.) Kunth)

9. Palmito cozido (Bactris gasipaes Kunth)

10. Palmito cru (Bactris gasipaes

11. Jambo (Eugenia malaccensis L.)

12. Pepino (Benincasa híspida (Thunb.) Cogn.)

13. Araçá-boi (Eugenia stipitata Mc Vaugh) Kunth)

14. Pupunha/fruto (Bactris gasipaes 

Ducke)

\section{Umari (Poraqueiba paraensis}

\section{Preparação dos Alimentos}

Os alimentos foram coletados na região de Manaus, ou seja, Estação Experimental de Fruticultura, Coordenação de Pesquisas em Ciências Agronômicas do Instituto Nacional de Pesquisas da Amazônia (INPA), situada no $\mathrm{km} 60 \mathrm{da} \mathrm{Br}$ 174, reserva particular no $\mathrm{km} 8$ da $\mathrm{Br} 174$ e feiras da cidade de Manaus, AM, de acordo com o período sazonal. Após a coleta os mesmos foram processados no Laboratório de Nutrição, da Coordenação de Pesquisas em Ciências da Saúde, Instituto Nacional de Pesquisas da Amazônia (INPA), de acordo com o consumo habitual, ou seja, após a remoção das sementes e cascas da graviola, abricó, manga, cupuaçu, pepino, araçá-boi e umari. Procedeu-se à secagem das polpas, em estufa ventilada com circulação de ar forçada a $60^{\circ} \mathrm{C}$ até peso constante. No que se refere à pupunha, o fruto, foi cozido por uma hora em temperatura de ebulição a fim de destruir os fatores antinutricionais. Em seguida, extraiu-se a casca e semente. $\mathrm{O}$ palmito foi cozido por trinta minutos em temperatura de ebulição, a fim de destruir os fatores antinutricionais seguido da secagem em estufa ventilada a $60^{\circ} \mathrm{C}$ até peso constante. Após a secagem, as amostras foram pulverizadas em moinho elétrico, homogeneizadas e acondicionadas em potes de polietileno previamente desmineralizados (banho de ácido nítrico $30 \%$ e enxague com água desionizada por 6 vezes) e enviadas à Supervisão de Radioquímica (IPEN/ CNEN-São Paulo) para análise.

\section{Preparação de Padrões Sintéticos}

Nesta etapa, como ocorre em todos os métodos comparativos, a preparação dos padrões é de extrema importância pois a exatidão dos resultados a ser obtida dependerá da qualidade dos padrões utilizados.

\section{Padrão sintético de Ca:}

A solução padrão de $\mathrm{Ca}$ foi preparada dissolvendo-se $\mathrm{CaO}(99,995 \%$ de pureza) em $\mathrm{HNO}_{3}$ concentrado P.A.

\section{Padrão sintético de Fe:}

Foi obtido a partir da dissolução de Fe em pó ( $99,99 \%$ de pureza), em ácido nítrico concentrado P.A. e algumas gotas de peróxido de hidrogênio, com pouco aquecimento.

\section{Padrão sintético de K:}

Foi obtido a partir da dissolução de $\mathrm{KBr}$ (com 99,99\% de pureza), em água destilada à temperatura ambiente.

\section{Padrão sintético de Na:}

Foi preparado calcinando-se $\mathrm{NaCl}$ P.A, a $800^{\circ} \mathrm{C}$ por 2 horas e a posterior dissolução em água destilada.

\section{Padrão sintético de Mn:}

A solução de Mn foi obtida a partir do reagente $\mathrm{MnO}_{2}$. O óxido de $\mathrm{Mn}$ foi previamente seco a $100^{\circ} \mathrm{C}$ por 1,5 horas e em seguida, dissolvido com ácido nítrico concentrado P.A. e algumas gotas de peróxido de hidrogênio, com pouco aquecimento.

\section{Padrão sintético de Se:}

A solução de Se foi preparada dissolvendo-se Se em pó, em uma 
mistura de $\mathrm{HNO}_{3} / \mathrm{HCl}$ concentrados, tomando-se o cuidado de manter a solução estoque em meio fortemente ácido para evitar hidrólise.

\section{Padrão sintético de Zn:}

A solução foi obtida dissolvendo-se Zn metálico em ácido nítrico P.A. diluído.

Os padrões sintéticos dos elementos a serem analisados foram preparados pipetando-se $50 \mu \mathrm{l}$ destes, e em alguns casos soluções multielementares, sobre uma tira de papel de filtro Whatman no. 41, a qual foi deixada à temperatura ambiente para sua secagem. Em seguida, essas tiras de papel foram acondicionadas em envelopes de polietileno, previamente limpos com ácido nítrico diluido e água destilada, e estes foram selados usandose ferro de solda.

Estas soluções padrão foram preparadas dissolvendo-se os elementos na forma de sais ou óxidos, espectroscopicamente puros, em ácidos inorgânicos em concentrações adequadas.

\section{Características Nucleares dos Radioisótopos}

A Tabela 1 apresenta as características nucleares dos radioisótopos analisados no presente trabalho
(AIEA, 1990).

\section{Preparação de Amostras e Padrões para irradiação}

Foram pesados cerca de $200 \mathrm{mg}$ dos alimentos e do material de referência Oyster Tissue em envelopes de polietileno, previamente limpos com $\mathrm{HNO}_{3}$ diluido e os padrões sintéticos dos elementos de interesse.

\section{Irradiação das Amostras e Padrões}

Na Análise por Ativação com Nêutrons Instrumental, amostras, material de referência e padrões sintético são irradiados no reator de pesquisa IEA-RI do IPEN-CNEN/São Paulo.

As amostras foram submetidas a dois tipos de irradiações:

\section{a - Irradiações curtas}

As amostras e padrões foram irradiados por 2 minutos, sob um fluxo de nêutrons térmicos de $10^{11} \mathrm{ncm}^{-2} \mathrm{~s}^{-1}$. Após um tempo adequado de resfriamento os seguintes elementos foram determinados: $\mathrm{K}$, Mn e Na.

\section{b - Irradiações longas}

As amostras e padrões foram irradiados por 8 horas, sob um fluxo

Tabela 1. Radioisótopos identificados na análise de alimentos por Ativação com Nêutrons Instrumental. (IAEA-TECDOC,1990)

\begin{tabular}{ccc}
\hline RADIOISÓTOPO & TEMPO DE MEIA VIDA & ENERGIA (KeV) \\
\hline${ }^{47} \mathrm{Ca}$ & 4,54 dias & $159 ; 1296$ \\
${ }^{24} \mathrm{Na}$ & 14,96 horas & 1368,68 \\
${ }^{4} \mathrm{~K}$ & 12,36 horas & 1524,58 \\
${ }^{59} \mathrm{Fe}$ & 44,5 dias & $1099 ; 1291,6$ \\
${ }^{75} \mathrm{Se}$ & 119,77 dias & $264 ; 400,7$ \\
${ }^{65} \mathrm{Zn}$ & 243,9 dias & 1115,6 \\
${ }^{56} \mathrm{Mn}$ & 2,58 horas & 846,$76 ; 1810,72$ \\
\hline
\end{tabular}


de nêutrons térmicos de $10^{13} \mathrm{ncm}^{-2} \mathrm{~s}^{-1}$. Após um tempo de decaimento de 4 a 5 dias, determinaram-se os radioisótopos de meia vida de algumas horas ou dias. Foram eles: Na e K. Após 15 a 20 dias de resfriamento determinaram-se os seguintes elementos: $\mathrm{Ca}, \mathrm{Fe}$, Se e $\mathrm{Zn}$.

\section{Tempos de Contagem}

Após irradiação com um tempo de decaimento de 5 dias, foi feita a primeira contagem com mais ou menos duas horas. Após 20 dias ou mais, foi feita uma segunda contagem com aproximadamente 15 horas, onde se determinaram os elementos de meias-vidas de vários dias.

Utilizando-se a AANI foi possivel a determinação da concentração dos seguintes elementos: $\mathrm{Ca}, \mathrm{Fe}, \mathrm{K}, \mathrm{Na}, \mathrm{Mn}$, Se e Zn.

\section{Método de análise por ativação com nêutrons instrumental}

O método de AANI foi testado quanto à sua precisão e exatidão por meio da análise dos materiais de referência certificados OYSTER TISSUE (NIST SRM 1566 A), CITRUS LEAVES (NBSSRM 1572) E TOTAL DIET (NIST-SRM1548) (RASBERRY, 1989). O material de referência Oyster Tissue que não sofreu nehum tratamento prévio, foi utilizado nas análises por apresentar valores certificados para todos os elementos determinados no presente trabalho e por dispor de uma maior quantidade desse material para poder realizar as análises.

Os materiais de referência Citrus Leaves e Total Diet foram utilizados apenas para verificação da exatidão dos padrões sintéticos preparados no laboratório. $\mathrm{Na}$
AANI, as amostras e os materiais de referência não sofrem nenhum processamento químico; eles são submetidos à irradiação com nêutrons no reator e posteriormente, são feitas as medidas da atividade gama induzida nos espectrômetros de raios gama. Utilizou-se a AANI comparativa onde em cada análise são irradiados, conjuntamente, 2 amostras (duplicata), uma amostra de material de referência (neste caso o Oyter Tissue) e os padrões sintéticos dos elementos a serem determinados. Para certificação dos padrões sintéticos, eles foram irradiados conjuntamente com os materiais de referência C. Leaves, Total Diet e Oyter Tissue. Dessa forma avaliou-se não somente a precisão (desvio padrão relativo) como também a exatidão (erro relativo) do método.

Os elementos $\mathrm{Na}$ e $\mathrm{K}$ podem ser determinados por meio de irradiações curtas e longas, dependendo da amostra. No presente trabalho, o K foi determinado somente por meio de irradiações curtas, pois apresenta uma meia vida de 12 horas e foi necessário esperar 5 a 7 dias de resfriamento para realizar a primeira série de contagem, nas irradiações longas. Dessa forma, praticamente todo o $\mathrm{K}$ já havia decaido. Com o Na isso não aconteceu, sendo possivel a sua determinação pelos 2 tipos de irradiações (além de uma meia vida maior, ele apresenta características nucleares mais favoráveis para ativação).

A análise por ativação com nêutrons baseia-se em reações que ocorrem com núcleos atômicos. Neste caso, nêutrons são as partículas ativadoras, que interagem com os núcleos de isótopos presentes em uma amostra ocorrendo a formação de isótopos radioativos por meio de reações nucleares. 
A probabilidade de que ocorra a reação nuclear, a abundância isotópica do núcleo alvo e a meia-vida do radioisótopo formado devem ter uma ordem de grandeza suficiente para que a análise se torne viável (KELLER, 1981).

Uma vez que cada isótopo produzido no processo de ativação possui caracteristica de emissão própria (meia-vida e energia das partículas ou radiação gama emitidas) é possivel efetuar determinações quantitativas da concentração por comparação com padrões.

A concentração é obtida pela comparação de áreas de picos referentes a padrões que são ativados juntamente com as amostras, utilizando-se para o cálculo a seguinte expressão:

$\mathbf{C}_{\mathrm{a}}^{i}=\left(\mathbf{A}_{\mathrm{a}}^{\mathrm{i}} \cdot \mathbf{m}_{\mathrm{p}} \cdot \mathbf{C}_{\mathrm{p}}^{i}\right) \cdot \mathrm{e}_{\mathrm{ap}}^{\lambda_{\mathrm{i}}(\mathrm{t}) / \mathbf{A}_{\mathrm{p}}^{i}} \cdot \mathbf{m}_{\mathrm{a} \text {, onde: }}$

$\mathrm{C}_{\mathrm{a}}^{\mathrm{i}}$ : Concentração do elemento $\mathrm{i}$ na amostra

$C_{p}{ }^{i}$ : Concentração do elemento i no padrão

$\mathrm{A}_{\mathrm{a}}{ }^{\mathrm{i}}$ : Atividade do elemento i na amostra padrão

$\mathrm{A}_{\mathrm{p}}{ }^{\mathrm{i}}$ : Atividade do elemento i no padrão

$m_{a}$ e $m_{p}$ : massas da amostra e

$\lambda$ : constante de decaimento do radioisótopo

$t:$ tempo de resfriamento

\section{Medidas de Radioatividade}

As medidas da radiação gama emitidas pelos diversos radioisótopos produzidos na irradiação das amostras são realizadas em espectrômetros de raios gama, constituídos de detectores de estado sólido, de Germânio-Lítio ou
Germânio puro, acoplados a analisadores multicanais e eletrônica associada e a micro computadores para análise dos dados. Foram utilizados 2 sistemas:

\section{Sistema 1}

Espectrômetro com Detector GEM 20190 POP TOP ligado à placa ORTEC ACE 4K acoplado a um microcomputador da linha IBM/PC. A resolução deste sistema foi de 1,56 $\mathrm{KeV}$ para o pico de $121,97 \mathrm{KeV}$ do ${ }^{57} \mathrm{Co}$ e de $2,20 \mathrm{KeV}$ para o pico de $1332,49 \mathrm{KeV}$ do ${ }^{60} \mathrm{Co}$.

\section{Sistema 2}

Espectrômetro com detector GEM 20190P ligado à placa ORTEC ACE 8K acoplado a um microcomputador da linha IBM/PC. A resolução deste sistema para o pico de $121,97 \mathrm{KeV}$ do ${ }^{57} \mathrm{Co}$ foi de $1,81 \mathrm{KeV}$ e de $2,28 \mathrm{KeV}$ para o pico de $1332,49 \mathrm{KeV}$ do ${ }^{60} \mathrm{Co}$.

Por meio dos espectros gama usando o programa de computação VISPECT2 em linguagem TURBO BASIC, foram obtidos os valores das energias dos raios gama dos radioisótopos formados e os valores das taxas de contagem pelo cálculo das áreas sob os picos. A identificação dos radioisótopos foi feita pela energia dos raios gama e suas meias vida (IAEA, 1990).

\section{RESULTADOS E DISCUSSÃO}

A Tabela 2 apresenta os resultados obtidos na certificação dos padrões sintéticos. A AANI é uma técnica analítica sensivel que pode ser utilizada para análises multielementares quali e quantitativas de elementos (macro e micro) em amostras de interesse 
Tabela 2. Resultados obtidos na certificação de Padrões Sintéticos com os Materiais de Referência OYSTER TISSUE (NIST-SRM-1566a), CITRUS LEAVES(NBS-SRM-1572) e TOTAL DIET (NIST-SRM1548). (Resultados em $\mu \mathrm{g} / \mathrm{g}$ ).

\begin{tabular}{|c|c|c|c|c|c|c|c|c|c|c|c|}
\hline \multicolumn{5}{|c|}{ OYSTER TISSUE } & \multicolumn{4}{|c|}{ CITRUS LEAVES } & \multicolumn{3}{|c|}{ TOTAL DIET } \\
\hline Elemento & $\begin{array}{l}\text { Valor } \\
\text { obtido }\end{array}$ & $\begin{array}{c}\text { Valor } \\
\text { esperado }\end{array}$ & $\begin{array}{l}\text { DPR } \\
(\%)\end{array}$ & $\begin{array}{l}\text { E.R. } \\
(\%)\end{array}$ & $\begin{array}{l}\text { Valor } \\
\text { obtido }\end{array}$ & $\begin{array}{c}\text { Valor } \\
\text { esperado }\end{array}$ & $\begin{array}{l}\text { DPR } \\
(\%)\end{array}$ & $\begin{array}{l}\text { E.R. } \\
(\%)\end{array}$ & $\begin{array}{l}\text { Valor } \\
\text { obtido }\end{array}$ & $\begin{array}{c}\text { Valor } \\
\text { esperado }\end{array}$ & $\begin{array}{l}\text { DPR } \\
(\%)\end{array}$ \\
\hline $\mathrm{Ca}$ & - & + & - & - & $29030 \pm 10$ & $31500 \pm 1000$ & 0,03 & 7,8 & $1699 \pm 172$ & $1740 \pm 70$ & 10,1 \\
\hline $\mathrm{Fe}$ & - & - & $=$ & c & $87,5 \pm 0,9$ & $90 \pm 10$ & 1,03 & 2,8 & $30,7 \pm 1,2$ & $32,6 \pm 3,6$ & 3,9 \\
\hline $\mathrm{K}$ & $6482 \pm 1136$ & $7900 \pm 470$ & 17,5 & 17,9 & - & - & - & - & - & - & - \\
\hline $\mathrm{Mn}$ & $12,7 \pm 0,5$ & $12,3 \pm 1,5$ & 3,9 & 3,3 & - & - & - & $=$ & * & - & - \\
\hline $\mathrm{Na}$ & $4133 \pm 49$ & $4170 \pm 130$ & 1,2 & 0,9 & $162 \pm 6$ & $160 \pm 20$ & 3,7 & 1,3 & $6252 \pm 188$ & $6250 \pm 260$ & 3,0 \\
\hline $\mathrm{Se}$ & - & - & $=$ & - & : & - & - & - & $=$ & $\cdot$ & - \\
\hline $\mathrm{Zn}$ & - & - & - & - & $26,7 \pm 0,3$ & $29 \pm 2$ & 1,12 & 7,9 & $28,9 \pm 1,6$ & $30,8 \pm 1,1$ & 5,5 \\
\hline
\end{tabular}

D.P.R. - Desvio padrão relativo

E.R. - Erro relativo

científico ou tecnológico.

O método AANI apresenta uma grande sensibilidade, precisão e exatidão para a maioria dos elementos de interesse nutricional. Além disso possui uma característica única entre os métodos analíticos usados para a determinação de elementos traço, que é a de não necessitar a análise de um branco analitico. A amostra uma vez irradiada com nêutrons produz isótopos radioativos, que são distinguidos dos não radioativos, por medidas em espetrômetros gama. A maior vantagem da AANI vem do fato de que a amostra não precisa estar em solução, particularmente conveniente para matrizes dificeis de se dissolver. A ausência da etapa de dissolução também proporciona ausência do branco analítico ou contaminação geralmente associados com os procedimentos de dissolução (HOFFMAN, 1992).

Uma outra vantagem da técnica de AANI é a quantidade de amostra necessária para análise que é muito pequena, da ordem de 100 a $200 \mathrm{mg}$, embora análises de amostras maiores também possam ser realizadas (VANDECASTEELE, 1991).

A AANI apresenta algumas desvantagens particularmente quando comparadas à outras técnicas analíticas como, por exemplo, o tempo de análise principalmente em se tratando de análises de rotina. Para muitos elementos que apresentam uma meia vida longa, da ordem de dezenas de dias ou mesmo anos, se faz necessário a espera de 2 a 4 semanas para quantificação desses elementos por meio de medida em espectrômetros gama. Uma outra desvantagem vem a ser a necessidade de um reator nuclear próximo ou outra fonte de partículas ativadoras para que se possa fazer as irradiações (VANDECASTEELE, 1991). Além disso, o método, como outros métodos de análise elementar, somente fornece informação de concentração total do elemento, não especificando a sua forma química e/ ou física (BODE, 1996).

De acordo com a Tabela 2, os elementos analisados apresentaram uma boa precisão (DPR $<10 \%$ ) e boa exatidão (ER < 8\%), com exceção do $\mathrm{K}$ com valores em torno de $17 \%$.

Embora se reconheça a essencialidade de 21 elementos minerais 
na Nutrição Humana, nem todos apresentam registros de deficiência, devido a sua ampla distribuição entre diferentes tipos de alimentos (HAZZEL, 1985). Entretanto, pouco se sabe sobre a composição de elementos minerais na maioria dos frutos e olerícolas da Região Amazônica que compõem a dieta da população Manauara (saudável ou enferma). Assim, determinou-se a concentração dos elementos: $\mathrm{Ca}, \mathrm{Fe}, \mathrm{K}, \mathrm{Mn}, \mathrm{Na}$, Se e Zn em $100 \mathrm{~g}$ da parte comestível de amostras dos alimentos: graviola, abricó, jaca (caroço e polpa), pupunha fruto, manga, cupuaçu, quiabo, palmito de pupunha (cozido e "in-natura"), jambo, pepino, araçá-boi, pupunha e umarí por Análise por Ativação com Nêutrons Instrumental e os resultados são apresentados na Tabela 3 .

Analisando individualmente os elementos minerais dos alimentos convencionais e não convencionais da região Amazônica, observa-se que a concentração de cálcio, foi maior no quiabo de metro $(45,8 \pm 1,0 \mathrm{mg} \%)$, seguido do palmito de pupunha cozido, in-natura e pupunha fruto. A menor concentração foi verificada no pepino $(4,5 \pm 0,2 \mathrm{mg} \%)$ e jambo $(6,7 \pm 0,6 \mathrm{mg} \%)$ (Tab. 3). Geralmente a quantidade de cálcio nos frutos e hortaliças é reduzida, quando comparada com o leite e derivados. Verifica-se que nas dietas de diferentes grupos populacionais, o cálcio é um dos elementos minerais mais limitantes (SHRIMPTON \& GIUGLIANO, 1979, LETHI, 1989, YUYAMA et al., 1992, YUYAMA \& COZZOLINO, 1995). Em relação aos valores da Tabela de
Composição de Alimentos (FIBGE, 1977), muitos dos frutos aqui analisados, apresentaram concentrações de cálcio superiores aos da maçã, pêssego e pera. O consumo de frutos e hortaliças pela população Manauara é limitado, necessitando de maior implementação quanto à utilização dos mesmos, objetivando a diversificação e maior aporte de nutrientes, como os elementos minerais.

Quanto ao ferro, o araçá boi apresentou quantidades expressivas $(619,2 \pm 14,4 \mu \mathrm{g} \%)$, seguido da pupunha, jaca caroço, pupunha $2^{\circ}$ variedade e cupuaçu. Valores inferiores foram encontrados no pepino $(86,3 \pm 3,6 \mu \mathrm{g} \%)$ e abricó $(120,8 \pm 15,9 \mu \mathrm{g} \%)$ (Tab.3). Quando se compara com os valores de Tabela de composição de alimentos (FIBGE, 1977), os frutos tradicionalmente conhecidos, como pera, maçã entre outros, apresentam valores inferiores aos de alguns frutos aqui analisados. A dificuldade de muitas pessoas em suprir as necessidades nutricionais, fica evidente em alguns trabalhos realizados na região Amazônica (SHRIMPTON \& GIUGLIANO, 1979, LETHI, 1989, YUYAMAet al., 1992). Há de se considerar ainda que nem todo o ferro presente nos alimentos, em especial os vegetais, é absorvido e utilizado pelo organismo, necessitando portanto, de mais estudos sobre a biodisponibilidade do ferro em dietas mistas, cujos ingredientes são consumidos em diferentes proporções e de maneira não uniforme em cada refeição. Além das diferenças entre o ferro hemínico e não hemínico, a biodisponibilidade do ferro não hemínico é fortemente 
Tabela 3. Resultados obtidos na determinação de elementos minerais nas amostras de alimentos por Análise por Ativação com Nêutrons Instrumental em $100 \mathrm{~g}$ da parte comestivel.

\begin{tabular}{|c|c|c|c|c|c|c|c|}
\hline & Ca mg & $\mathrm{Fe} \mu \mathrm{g}$ & $\mathrm{K} \mathrm{mg}$ & $\mathrm{Na} \mu \mathrm{g}$ & $\mathrm{Mn} \mu \mathrm{g}$ & Se $\mu \mathrm{g}$ & $\mathrm{Zn} \mu \mathrm{g}$ \\
\hline Graviola & $11,7 \pm 0,7(3)$ & $337,0 \pm 23,4(4)$ & $313,2 \pm 16,1(4)$ & $1053,0 \pm 46,8(6)$ & $81,3 \pm 0,2(5)$ & $8,2 \pm 0,2(4)$ & $181,3 \pm 9,7(4)$ \\
\hline Abricó & $8,0 \pm 0,4(3)$ & $120,8 \pm 15,9(4)$ & $31,8 \pm 3,6(4)$ & $1756,8 \pm 97,6(8)$ & $20,0 \pm 0,7(2)$ & $0,8 \pm 0,08(1)$ & $181,8 \pm 9,7(4)$ \\
\hline Jaca caroço & $13,6 \pm 1,9(4)$ & $488,0 \pm 52,0(4)$ & $425,3 \pm 0,6(4)$ & $256,0 \pm 2,0(2)$ & $346,0 \pm 34,0(9)$ & ND & $836,0 \pm 28,0(4)$ \\
\hline Jaca polpa & $13,4 \pm 0,5(3)$ & $258,6 \pm 9,8(4)$ & $305,4 \pm 27,2(4)$ & $97,6 \pm 24,4(6)$ & $300,1 \pm 17,1(4)$ & $0,6 \pm 0,1$ & $234,2 \pm 19,5(4)$ \\
\hline Pupunha 2 var. & $10,2 \pm 0,5(3)$ & $474,7 \pm 9,4(4)$ & $225,8 \pm 0,3(2)$ & $178,6 \pm 14,1(4)$ & $115,1 \pm 3,3(9)$ & $3,3 \pm 0,2(4)$ & $258,5 \pm 18,8(4)$ \\
\hline Manga & $8,8 \pm 0,3(3)$ & $210,6 \pm 11,3(4)$ & $239,5 \pm 15,6(2)$ & $341,8 \pm 15,4(4)$ & $50,2 \pm 4,9(9)$ & $0,6 \pm 0,01(3)$ & $142,6 \pm 4,9(6)$ \\
\hline Cupuaçu & $7,3 \pm 0,1(2)$ & $407,4 \pm 1,2(4)$ & $207,5 \pm 45,7(1)$ & $127,7 \pm 0,3(2)$ & $174,7 \pm 3,4(9)$ & $0,7 \pm 0,1(2)$ & $295,7 \pm 13,4$ (4) \\
\hline Quiabo & $45,8 \pm 1,0(2)$ & $311,2 \pm 16,4(4)$ & $101,6 \pm 22,2(1)$ & $2135,7 \pm 69,3(2)$ & $15,1 \pm 1,3(9)$ & ND & $143,0 \pm 6,3(4)$ \\
\hline Palmito cozido & $42,9 \pm 3,7(4)$ & $265,2 \pm 28,6(6)$ & $127,8 \pm 0,7(2)$ & $114,4 \pm 7,8(4)$ & $256,7 \pm 1,3(9)$ & $2,8 \pm 0,05(4)$ & $367,2 \pm 5,8(4)$ \\
\hline Palmito cru & $42,4 \pm 2,9(2)$ & $233,7 \pm 19,5(6)$ & $193,7 \pm 4,8(2)$ & $103,7 \pm 5,1(4)$ & $355,3 \pm 28,0(9)$ & $2,1 \pm 0,02(4)$ & $494,7 \pm 5,1(4)$ \\
\hline Jambo & $6,7 \pm 0,6(3)$ & $285,0 \pm 32,3(4)$ & $127,8 \pm 1,6(1)$ & $2118,5 \pm 285,0(4)$ & $36,8 \pm 5,1(9)$ & $0,2 \pm 0,07(2)$ & $560,0 \pm 1,9(4)$ \\
\hline Pepino & $4,5 \pm 0,2(2)$ & $86,3 \pm 3,6(4)$ & $63,7 \pm 1,1(2)$ & $647,9 \pm 45,6(1)$ & $8,4 \pm 0,4(4)$ & ND & $37,4 \pm 0,6(4)$ \\
\hline Araça-Boi & $9,4 \pm 0,6(2)$ & $619,2 \pm 14,4(4)$ & $62,7 \pm 1,8(2)$ & $144,7 \pm 10,8(3)$ & $39,6 \pm 1,4(9)$ & $0,6 \pm 0,01(4)$ & $104,4 \pm 2,9(4)$ \\
\hline Pupunha & $24,7 \pm 2,1(4)$ & $565,6 \pm 15,1(4)$ & $289,3 \pm 3,0(2)$ & $242,4 \pm 25,2(2)$ & $84,3 \pm 6,1(5)$ & $3,5 \pm 0,1(2)$ & $277,7 \pm 5,5(4)$ \\
\hline Umari & $23,0 \pm 2,5(4)$ & $360,7 \pm 2,8(4)$ & $208,6 \pm 13,7(2)$ & $620,6 \pm 56,4(3)$ & $212,7 \pm 12,3(6)$ & $1,6 \pm 0,1(4)$ & $222,9 \pm 3,2(4)$ \\
\hline
\end{tabular}

(n) - número de determinaçòes 
influenciada por vários componentes da dieta. Assim, a absorção do ferro não heminico aumenta em presença de carnes e ácidos ascórbico (VANNUCCHI et al., 1992). Desta forma, sugere-se à utilização por exemplo, do camu-camu (Myrciaria dubia H.B.K.), que é uma fonte rica em ácido ascórbico (ANDRADE et al., 1992), para tornar o ferro de origem vegetal biodisponivel. Obviamente, vários outros fatores devem ser levados em consideração para a adequada interpretação da qualidade das fontes alimentares de ferro.

De todos os minerais analisados, o potássio, se sobressaiu, com maiores concentracões na jaca caroço $(425,3 \pm 0,6 \mathrm{mg} \%)$, seguido da graviola, jaca polpa e pupunha. Menor concentração no araçá boi $(62,7 \pm 1,8$ $\mathrm{mg} \%)$ e pepino $(63,7 \pm 1,1 \mathrm{mg} \%)$ (Tab.3). O potássio é largamente distribuido nos alimentos, uma vez que é um dos constituintes essenciais das células. De acordo com a Tabela de composição de alimentos (FIBGE, 1977), verifica-se que os frutos, olerícolas, cames e cereais, são boas fontes de potássio. Os resultados apresentados na Tabela 3 , confirmam quantidades relevantes nos frutos analisados.

No que se refere ao sódio, quiabo de metro desponta com uma concentração de $(2135,7 \pm 69,3 \mu \mathrm{g} \%)$, seguido do jambo, abricó e graviola. Jaca polpa $(97,6 \pm 24,4 \mu \mathrm{g} \%)$, seguido do palmito cru $(103,7 \pm 5,1 \mu \mathrm{g} \%)$, apresentaram menor concentração (Tab.3). A alta ingestão de sódio está normalmente associada com alimentos processados e a baixa, com alimentos de origem vegetal, como frutos frescos, vegetais e legumes (RDA, 1990). De acordo com os resultados obtidos (Tab.3), verifica-se que as concentrações são baixas. Os resultados obtidos para $\mathrm{Na}$ por meio de irradiações curtas e longas foram bastante concordantes obtendo-se, em geral, uma melhor precisão nos resultados obtidos por meio de irradiações longas

Em relação ao manganês, o palmito cru apresentou um teor de $(355,3 \pm 28 \mu \mathrm{g} \%)$, seguido da jaca caroço, polpa e palmito cozido. Concentração reduzida para a manga $(3,1 \pm 0,3 \mu \mathrm{g} \%)$ e pepino $(8,4 \pm 0,4 \mu \mathrm{g} \%)$, (Tab.3). Geralmente, as frutas e os vegetais são boas fontes de manganês, entretanto depende do conteúdo deste elemento no solo.

O selênio, foi um dos poucos elementos minerais, que apresentou baixa concentração, e em muitos dos alimentos analisados (jaca caroço, quiabo e pepino) se encontrava abaixo dos limites de deteção $\left(L_{D}\right)$ da técnica $\left(\mathrm{L}_{\mathrm{D}}=20 \mathrm{ng} / \mathrm{g}\right)$. Entretanto, outros frutos, como a graviola, seguido de pupunha fruto e palmito apresentaram teores que podem contribuir no aporte de selênio. Frutos e vegetais, geralmente contêm pouco selênio. A concentração do mesmo, nos alimentos, depende do conteúdo de selênio no solo nos quais crescem. Ao contrário dos demais elementos minerais traços, o selênio contido na dieta da população Manauara na ocasião do estudo, foi o que apresentou maior teor em relação a de São Paulo, Mato Grosso e Santa Catarina (YUYAMA \& COZZOLINO, 1995).

O selênio é um elemento com 
características nucleares favoráveis para a sua ativação. Embora tenha uma abundância isotópica baixa $(0,9 \%)$ apresenta uma secção de choque de ativação com nêutrons térmicos de 51,2 barns, valor esse bastante alto. $\mathrm{O}^{75} \mathrm{Se}$ é formado pela reação nuclear ${ }^{74} \mathrm{Se}(\mathrm{n}, \gamma){ }^{75} \mathrm{Se}$. A obtenção de concentrações com elevada precisão e exatidão, permite dizer que os resultados são plenamente confiáveis, pois foram quantificados não somente pelo padrão sintético de Se como pelo material de referência $\mathrm{O}$. Tissue, que possue valor cerfificado de $2,21 \pm 0,24 \mu \mathrm{g} / \mathrm{g}$ para Se. Nas amostras em que não foi possivel a quantificação do Se, foi devido a baixa concentração desse elemento (abaixo do limite de detecção de $20 \mu \mathrm{g} / \mathrm{g}$ ).

Uma outra limitação em relação aos elementos minerais na dieta da população Manaura é o zinco (SHRIMPTON \& GIUGLIANO, LETHI, 1989, YUYAMA et al., 1992). As concentrações foram elevadas na jaca caroço $(836 \pm 28 \mu \mathrm{g} \%)$, jambo, palmito cru e cozido e menor concentração no pepino $(37,4 \pm 0,6 \mu \mathrm{g} \%)$ e araçá boi $(104,4 \pm 2,0 \mu \mathrm{g} \%)$. Comparando-se com os dados de literatura, verificou-se valores superiores de zinco na pupunha, araçá boi e jaca polpa (LEHTI, 1993) e valores semelhantes para o umarí (ROCHA \& SHRIMPTON, 1984).

Desta forma, os elementos minerais existentes nos frutos e olerícolas da Região Amazônica, podem ser implementados para compor a alimentação da população Manauara. Ressalta-se ainda, que a dieta de um indivíduo é mais abrangente, constituida de produtos de origem animal e vegetal, o que permite maior diversificação e possibilidade de adequação.

De acordo com a pirâmide de guia alimentar (GORDON, 1995), a recomendação para o grupo de verduras é de 3 a 5 porções de alimentos. Obviamente os alimentos podem ser substituidos pelos regionais, entre eles, quiabo de metro, palmito e pepino. Quanto aos frutos, de 2 a 4 porções de: pupunha (fruto), jaca caroço, jambo, araçá boi, cupuaçu entre outros. Ressalta-se ainda que a pirâmide de guia alimentar é constituida por outros grupos de alimentos que devem fazer parte da alimentação diária de um indivíduo.

Os resultados existentes na literatura são dispersos e muitas vezes a metodologia não é detalhada, tornandose as comparações pouco conclusivas. Adicionalmente, as concentrações de elementos minerais, nos alimentos, podem variar de acordo com as condições de solo, maturação, armazenamento e métodos utilizados, contribuindo assim, para possíveis variações nas análises nutricionais.

De um modo geral, os alimentos analisados possuem concentrações variadas de elementos minerais, sobressaindo-se o potássio com teores expressivos para a maioria dos frutos e olerículas e menor concentração para o selênio. Teores de cálcio foram observados no quiabo de metro, pupunha fruto e palmito de pupunha, zinco (jaca caroço, jambo e palmito de pupunha) e ferro (araçá boi, pupunha fruto, jaca caroço e cupuaçu), contribuindo dessa forma, para a implementação quanto à recomendação, utilizando-se alimentos regionais 
potencialmente nutritivos, objetivando a minimização das carências nutricionais na região.

\section{CONCLUSÃO}

A técnica de Análise por Ativação Neutrônica Instrumental foi muito sensivel para a determinação de elementos minerais em alimentos, apresentando resultados precisos e exatos.

Os alimentos convencionais e não convencionais, apresentaram concentrações variadas de elementos minerais, sobressaindo-se o potássio com teores expressivos para a maioria dos frutos e olericolas analisados, assim como concentraçoes importantes de cálcio, zinco e ferro e menor concentração para o selênio, contribuindo dessa forma, para a implementação quanto à recomendação e utilização dos mesmos na alimentação da população Manauara.

\section{AGRADECIMENTOS}

Agradecemos o suporte financeiro do $\mathrm{CNPq}$ para a realização desse trabalho.

\section{Bibliografia Citada}

AGUIAR, J.P.L.; MARINHO, H.A.; REBELO, Y.S.; SHRIMPTON, R. 1980. Aspectos nutritivos de alguns frutos da Amazônia. Acta Amazonica, 10: 755-58.

ANDRADE, J.S; ARAGÃO, C.G; FERREIRA, S.A.N. 1992. Caracterização física e quimica do camu-camu (Myrciaria dubia (H.B.K.) Mc Vaugh. Anais, XIII Congresso Brasileiro de Ciência e Tecnologia de Alimentos. São Paulo, p. 327.

BODE, P. 1996. Instrumental and Organizational Aspects of a Neutron Activation analysis Laboratory, Interfaculty Reactor Institut, Delft University of Technology, The Netherlands, p. $40-41$.

CHATT, A.; DANG, H.S.; FONG, B. B.;
J A YA W I C K R E M E, C. K . ; MCDOWELL,L.S; PEGG,D.L. 1988. Determination of trace elements in foods by neutron activation analysis. J. Radioanal. Nucl. Chem., Articles, 124 (1); 65-77.

CLEMENT, C.R.; SILVA FILHO, D.F. Amazonian small fruits with commercial potential. Fruits Varieties j. s.1., v. 48 , n.3, p. 152-158, 1994.

CUNNINGHAM, W.C. 1987. Radiochemical Determination of $\mathrm{As}, \mathrm{Cr}, \mathrm{Mo}, \mathrm{Sb}$, and $\mathrm{Se}$ in foods. J. Radioanalytical and Nuclear Chemistry, Articles, 113 (2): 423-30.

FUNDAÇĂO INSTITUTO BRASILEIRO DE GEOGRAFIA E ESTATÍSTICA (FIBGE). 1977. Estudo Nacional de Despesas Familiares: Consumo alimentar. Dados preliminares. Tabelas selecionadas. $208 \mathrm{p}$.

GORDON, M.W. 1995. Perspectives in nutrition. 3 ed. Wardlaw Insel, p. 34.

HAZELL, T. 1985. Mineral in foods: Dietary source, chemical forms, interactions, bioavailability. World Rev. Nutr. Diet., 46: 1-123.

HOFFMAN, E.L. 1992. Instrumental Neutron Activation in Geoanalysis. $J$. of Geochemical Exploration., 44: 297-319.

JIMBA,B; IGE, T. 1990. Concentration of Cr, $\mathrm{Fe}, \mathrm{Co}$, and $\mathrm{Zn}$ in some Nigerian food grains. J. Radioanal. Nucl. Chem., Letters, 144 (6);447-52.

KELLER, C. 1981. Radioquímica. Editora Universitária - Universidade de Pernambuco, Recife, :305-313.

LEHTI, K.K. 1989. The iron, folic acid and zinc status of low socio-economic pregnant and lactating amazonian women. Eur. J. Clin. Nutr., 43:503-13.

LEHTI, K.K. 1993. Composição nutricional de alguns alimentos da Amazônia Brasileira - Resultados Preliminares. Rev. UA, Série: Ciência da Saúde, 2(1-2): 139-47.

LIU, S. M.; CHUNG,C.1992. Trace elements in Taiwanese Diet in different seasons. J. Radioanal. Nucl. Chem., Articles, 161(1): 27-38.

MANNAN, A; WAHEED, S; QURESHI, I.H. 1990. Concentration and distribution of toxic 
elements in rice and husk. $J$. Radioanal. Nucl. Chem., Articles, 140 (1); 91-102.

NATIONAL ACADEMY OF SCIENCE/ NATIONAL RESEARCH COUNCIL. 1989. Recommended Dietary Allowances. 10 ed. Washington, 284p.

PARR, R.M. 1987. Applications of Nuclear Analytical Techniques in Human Nutrition Research as Exemplified by Research Programmes of the IAEA. $J$. Radioanal. Nucl. Chem., Articles, 110 (2): 491-502.

Practical Aspects of Operating a Neutron Activation Analysis Laboratory - IAEA. 1990 - TEC DOC - 564, Viena,

RASBERRY, S.D. 1989. Office Standard Reference Materials. National Institute of Standards \& Technology, Certificate of Analysis.

ROCHA, Y.R; AGUIAR, 1982. JP.L; MARINHO, H.A., SHRIMPTON, R. Aspectos nutritivos de alguns peixes da Amazônia. Acta Amazonica, v.12, n.4, p. 787-94.

ROCHA, Y.R; SHRIMPTON, R. 1984. Conteúdo de zinco em alimentos selecionados da Amazônia. Tecnologia de Alimentos, 4: 68-78.

SCHELENZ, R. 1977. Dietary intake of 25 elements by man estimated by neutron activation analysis. J. Radioanal. Chem. 37 (2):539-48,

SHRIMPTON, R; GIUGLIANO, R. 1979. Consumo de alimentos e alguns nutrientes em Manaus, 1973-74. Acta Amazonica, 9 (1): 17-41.
TRANVAN, L; TEHERANI, D.K. 1988. Determination of $\mathrm{Au}, \mathrm{Sb}, \mathrm{As}, \mathrm{Br}, \mathrm{Na}, \mathrm{K}, \mathrm{Cd}$, $\mathrm{Mn}$ and $\mathrm{Cl}$ in Rice from Vietnam by Instrumental Neutron Activation Analysis. J. Radioanal. Nucl. Chem., Letters, 128 (1): 43-51.

VANDECASTEELE, C. 1991. Activation analysis: Present Status in Relation to Other Analytical Techniques. Mikrochim. Acta [Wien], II: 379-89.

VANNUCCHI, H; FREITAS, M.L.S.; SZARFARC, S.C. 1992. Prevalência de anemias nutricionais no Brasil. Cadernos de Nutrição, 4 :7-26.

YUYAMA, L.K.O; COZZOLINO, S.M.F.; ROCHA, Y.R. 1992. Composição química e percentual de adequação de dieta regional de Manaus, AM. Acta Amazonica, 22 (4): 587-93.

YUYAMA, L.K.O; COZZOLINO, S.M.F. 1995. Determinação dos teores de $\mathrm{Zn}$, $\mathrm{Fe}, \mathrm{Ca}, \mathrm{Se}, \mathrm{Cu}, \mathrm{K}$ e $\mathrm{Mn}$ na dieta regional de Manaus, AM. Rev. Inst. Adolfo Lutz, 55: 45-50.

WOITTIEZ, J.R.W.; IYENGAR, G.V, 1988. The use of neutron activation in dietary reference material analysis. Fresennius Z. Annal. Chem., 332: 657-61.

ZAIDI, J.H.; QURESHI, I.H.; ARIF, M.; FATIMA, I. 1992. Trace Element Analysis of Food Spices by Instrumental Neutron Activation Analysis. II. Solanaceae, Liliaceae, Zingiberaceae and Apiaceae Families, Int. J. Environm. Anal. Chem. 48: $33-40$. 